\title{
The Paradox of Schizoid Self: A Critical Reflection on Gender and Spirituality in Uzma Aslam Khan's The Geometry of God
}

* Sadia Akram, PhD Scholar \& Lecturer (Corresponding Author)

** Dr. Mazhar Hayat, Professor

\begin{abstract}
This study seeks to explore the paradox of Schizoid-self, which is split, fluid and in a constant flux, since it is situated in the interstitial space of gender and spirituality in Uzma Aslam Khan's The Geometry of God (2008). The present study aims to yoke together Postmodernist implicit dangers of centrelessness, divergence, fragmentation, and chaos on a central pivot to bring resolution, harmony, and reunion in both distinct and shared human experiences. This research employs Postmodernist notions of Gilles Deleuze and Felix Guattari (1972/1977) about Schizoid-self and further juxtaposes in a single real space several incompatible spaces to unearth the interlink between gender and spirituality. This inquiry is informed by deconstructionist ways of interpreting text through the interstitiality of schizoid-self and gender with its potentials and perils and, thus, traces its spiritual purpose. The present study proposes a circular connection between gender, spirituality and multifaceted self and marks it a way forward in resolving the conflict between males and females regarding their practical and mystical outlook. Moreover, the findings reveal and underwrite that pluralism is a measuring stick of human rights and gender justice in this age of human crisis.
\end{abstract}

Keywords: Paradox, Schizoid-self, Critical Reflection, Gender, Spirituality, Interstitial Space.

\section{Introduction}

This study attempts to find out the significance of both male and female spirituality in resolving the crisis of Postmodernist schizoid self. The implied danger of schizoid self with its perils and promises offers a circular interpretation through the interstitial space of self, gender and spirituality in Uzma Aslam Khan's The Geometry of God (2008). Postmodernist Schizoid-self has always been formidable, similar to this, Akram (2012) describes schizoid/split self as passionate and "threatening", due to its lack of differentiating between truth and illusion (p. 34). Consequently, the problematic of self as a human identity crisis requires divine restoration, resolution, harmony, and reunion in both individual and collective (male and female) real-life experiences.

\section{The Paradoxical Nature of Schizoid-Self}

The Schizoid- self is paradoxical in nature with its crisis and potential, as, a conflicted self struggles to come out of self-inflicted alienation and immediately strives to connect with others owing to the fact that one's survival depends on others. In this context, Ricoeur (1986/1994) asserts a strong link between the selfhood and other by stating that individuality denotes difference and "vice versa", in other words, it suggests that the selfhood signifies otherness (p.3). Moreover, a purposeful life always recognizes both oneself and other, for this reason, a center is always prerequisite, around which human life can move in a composite circle. But, things fall apart due to lack of one's self recognition and worth, therefore, the self in identity-crisis also cannot comprehend the value of others. In a similar vein, Watson (1928) highlights the chaos and disorder of modern age by referring to the fact that we lack any focal point due to which things are in a chaos and require an urgent fix. Thus, this study attempts to unearth the interlink between gender and spirituality and also seeks to present it as a way forward to the paradox of schizoid-self by neutralizing the rift both in human and gendered forms through graciously accepting human plurality and diversity. Since, spirituality transcends all barriers of self and other by not strictly taking into account the numerical equivalence between genders, rather it considers no gender is superior or inferior in the eyes of the Creator, hence the spiritual self potentially works to determine the conflict between self and other or males and females in terms of their practical and spiritual outlook by unearthing the interstitial/intersectional space of schizoid self, gender and spirituality. In this context, the idea of acknowledging pluralism and diversity through

Department of English, Government College University, Faisalabad Email: sadia_akram1 @hotmail.com ** Department of English, Government College University, Faisalabad Email: mazharhayat63@gmail.com 
tolerance and compassion may serve as a foundation of human rights and gender justice. Therefore, this inquiry explores the interstitiality and intersectionality of self and other (male, female) and poses the following point of departure to be addressed:

*How does Khan (2008) in The Geometry of God impart harmony through pluralism and bring spiritual rebirth by exploring the interstitial/intersectional link between Schizoid self, gender and spirituality in resolving the human crisis?

\section{Pluralism and Gender Justice in Unravelling the Schizoid-Self}

Pluralism in the pursuit of spiritual rebirth dismantles all the bifurcations and distinctions of border, land, faith and gender. It has been a general practice in almost all disciplines of human knowledge to highlight the difference between genders based on their social traits, something that Beauvoir (1949/ 2011) has termed as social ontology. In this perspective, women are considered to be weak, inferior, foolish, emotional and unprivileged, while, men are described as strong, superior, intelligent, practical and privileged. In the backdrop of this male and female social divide, an air of antagonism ensues and creates a rift and a marked distinction between men and women, which instantly needs to be resolved.

\section{Significance of the Interstitial/Intersectional Space}

Felluga (2015) defines intersectionality in relation to identity politics, which directly relates to this research, as it has potential to offer the interstitial space of gender and spirituality based on the principal of tolerance and diversity. According to him, instead of pursuing a single perspective to question individuality, "Intersectionality considers the multiple markers of identity (race, class, gender, sexuality) that can together exacerbate exclusion and oppression in our culture" (p. 156). In this state, there is always a need to create some space for the inclusion of others, so that the intensity of conflicts and unjust bifurcations could be pacified through intersectional links between self and other (male and female) to appease the rift and antagonism in society.

\section{Significance of the Study}

This study is substantial since it attempts to deal with the contemporary challenges that all of us, as human beings face and feel perturbed and devastated due to identity crisis and frictions between self and other. In order to resolve conflicts, antagonisms and rifts in real-life human experiences, this research calls for an urgent fix, as it is a conscious endeavor to unearth the signification of plurality, diversity and gender justice for understanding the paradox of schizoid self as well as the spiritual journey of any seeker. In other words, it seeks to decipher and resolve the human crisis in relation to self and other, since, the idea of multiplicity and gender justice is humanizing, for it transcends all boundaries that separate human beings from each other on the practical and spiritual planes.

In the light of above cited views, we can grasp that both men and women are part and parcel of each other, as, they are not opposites, but different. Though, they are equal according to the standards of humanity, yet are different due to their oppressive as well as liberating cultural constructs based on their social ontology as stated before. Echoing the same, Islam considers both men and women as equal, for instance, Quran enunciates that God has made human beings "from a single of a male and a female, and made you into nations and tribes that you may know each other. Verily the most honored of you in the sight of Allah is the most righteous of you". (Pickthall, 1930, 49:13).

\section{Literature Review}

\section{Postmodernist Multi-layered Identity Politics}

The Postmodernist incredulity towards established norms led us to challenge and question everything, even the notion of self-identity and binary oppositions. As Best and Kellner (1991) highlighted the worth of liberation from everything that enslaves human beings by referring to Lyotard's (1979/1984) incredulity towards traditional concepts of reality and contemplated that "Lyotard's rejection of metanarratives disabled construction of narratives of why inequality or women's suppression is illegitimate and why women's liberation is justified?" (1991, p.209). Therefore, postmodernists celebrate the politics of difference too, as, Best and Kellner described, "The politics of difference has emerged as a project of building new political groupings with categories neglected in the previous modern politics such as race, gender, sexual preference, and ethnicity" (p.205).

In a similar fashion, D. S Ahmed (2002) acknowledged the significance of postmodernist diversity and multiplicity of ways in order to be united with the Divine, as she elucidated in the following words, "diversity has had theological precursors who argued that diversity between and within different religious beliefs reflects the infinite and creative dimensions of the Divine, each is valuable, highlighting different facets of nevertheless essential Unity." (p.24). She continued 
explaining that various flairs of perception signify diverse views "on life, events, relationships" and unveil several collective, yet, distinct abilities of "both sexes" (p.75).

Race and Location in Forming Human Identity

Khan, Saigol and Zia (1994) observed the substance of race and location in perceiving human identity, as they explained: "one's class position is mediated by one's gender and gender is mediated by class and/or race" (Introduction, p.1). It illustrates that human identity is determined by race, geography and class. In other words, two men or women, who belong to a different race, geography and class have different identity, despite of having the same gender.

Roald (2001) identified the above stated idea with a slight difference by taking identity, "as those factors of a person's or a group's belief-system, nationality, ethnicity and class, educational background, rural or urban background, gender or sexuality" (p.14). To put it in another way, Roald asserted human identity as negotiable due to its flexibility and adaptability according to the changing places and situations. The argument of Roald paves way for the present study's egalitarian stance, as it also supports and intersects both male and female views in the following words, "feminists tend to exclude the male perspective in favour of the female while I consider it important to include both men and women in the process of interpreting Islamic sources" (Preface, p. xi).

\section{Role of Language and Subjectivity}

Language plays a significant role in the process of meaning making, even though, we know that words cannot be equated with reality of life, because the power of actions is more than that of words. In this context, Tolle (2016) questioned, "Do you believe some combination of such basic sounds could ever explain who you are or the ultimate purpose of the universe"? (p.27) According to Gutting (2005), unlike Tolle, Foucault's postulation of language contains a space which necessarily "takes us beyond the mode of subjective and even inter-subjective expression" (p.8), which means, both, losing oneself in language as well as finding self- expression in it.

D. S Ahmed (1994) inspired by Freud and Jung talked about language skill in constructing or deconstructing human consciousness. According to her, "Our ability to reflect on ourself and in turn convey the mechanism (logic) and fruit of this reflection is wholly dependent on words." (Introduction, p.8). Ahmed's idea about the power of words contributes to this inquiry of understanding all forces that constitute human identity.

\section{Gender Politics and Dichotomy between Men and Women}

The issue of gender politics has always been a matter of debate in all ages, for example, Aristotle (1254b, 1921) considered men superior to women since, by nature, the former controls and the latter is controlled. For him, men were innately stronger than women biologically as well as intellectually. Somewhat similar to Aristotle's harsh comments, Nietzsche $(1885,2008)$ also turned out to be a hater of women, due to his belittling comment, by calling women just a source of enjoyment and pleasure. Russell (1945) countered Nietzsche's view as the venom of his tongue due to his frustrated pursuit of personal love because it is not suitable for a philosopher to be bitter in his views.

Contrary to the above discussed idea, Aftab (2011) provided another angle to the debate by asserting an independent perspective according to which, she situated one's identity (male and female) as a necessary ingredient of taking an individual social position for the recognition of one's agency and subjectivity, which is somewhat similar to Gadamer's (1960/2004) thesis of supporting prejudice as an obvious and indispensable state of "being and knowing", in which instead of recognizing only one party's position, both sides of the binary (male and female) get equal right and fuse his and her horizon of understanding in order to pursue the process of being and knowing by positively enabling their prejudice without frictions.

\section{A Worldview of Equitable Society}

Sardar (1988) illustrated the idea of equitable society, but with a slight difference from others by proving Islam as a positive way of living, based on justice and equality. For him, Islam is holistic, since, it invites thought to determine the resolution of the existing "crisis of modernity and postmodernism" (Introduction, Inayatullah \& Boxwell, 2003, p.5).

Similarly, Akram (2019) put the following view of deconstructing the binary between "you and me" based on the spirituality of Shah (2008), "when one is in a state of purely spiritual love, then all boundaries between you and me are deconstructed" (p.91). Further, she enunciated the related idea of self and other inspired by Whitman (1982), claiming that a spiritual person links to all, regardless of class, gender and culture. 
Echoing the totalitarian authority postulated by Foucault, Iqbal (2003) advocated a dissimilar notion, but, similar to the above cited idea in his letter to Nicholson i.e. "an egalitarian spirit" as for him, the objective of his writing is "to discover a universal social reconstruction" by going beyond all divisions (Frick, Qasmi, \& Rostetter, 2011, p.16).

\section{Counter Discourse against Gender Roles Based on Biology}

Al- 'Arabi' (1229a/1980) reflected on the gendered dimension of the divine and viewed both sexes as complementary. He considered Adam as the first female since, "in that Eve was born from his side" (p.32). He also described Mary "as the second Adam in that she generated Jesus" (p.35). The metaphor of Adam and Eve in Arabi (1229b/ 1984) construes "the creative breath of Mercy, a component of the Godhead itself, as feminine" (p. 8-9). Parallel to this, Soul (2015) contemplated on a man's strength as following, "a secure man understands that the strength of the relationship is found in the union and not the individual" (p.38).

\section{The Role of Acceptance in Resolving the Human Crisis}

The cause of human suffering is our evolving ego, which, we need to diminish in order to be empathetic and compassionate, regardless of our race, culture, religion and gender. Time and again, while we are in a state of crisis, then and there, we strive to get back our lost courage. In this attempt, we struggle to strengthen our spiritual connection with others as well as with our Creator. For this purpose, we seek guidance from God by invocation as Bell and Littleton (2007) resonated Niebuhr's (1951) prayer by invoking God to bestow upon us anything that is bound to remain unaltered with peaceful elegance, grant us audacity to alter anything that must be altered and also "the wisdom to distinguish one from the other" (2007, p.14). The same prayer Sharma (2016) also recommended since the aforementioned plea refers to the importance of accepting change as well as differentiating between self and other so that the opposition and the clash of opinions may be resolved peacefully with tolerance, first by distinguishing the one from the other and then recognizing both individually as well as collectively (p. 199).

\section{Theoretical Framework and Methodology}

This study is based on postmodernist notions of schizoid self with reference to Deleuze and Guattari (1972/1977), as, they honour free play of language and break the binary between male superiority and female inferiority. This dismantling of bifurcation allows diversities, although, it is a deconstruction of opposites, yet is a reconstruction of different entities into a plural and cohesive whole, which is the main objective of this study. Lyotard (1983/1988) takes this difference as differnd, according to him, differnd is a case of conflict at least between two parties, The resolution of this conflict/ differnd can be done through new modes of representation that allow the expression of the victim and the culprit alike (p.13). Thus, it creates a room for the multiplicity of voices.

In the wake of the above discussed division between males and females, the schizoid self can be seen as a combination of multiple identities due to its constant process of assembling and dividing itself. We are playing many roles at a time as a daughter or son, as a wife or husband, as a mother or father, hence different relations, multiple professions and roles demand different characteristics. Consequently, we deal with different people on different occasions, according to our status and situation, which, in no way makes us superior or inferior but different and equal.

Echoing the same, Best and Kellner (1991) inspired by Deleuze and Guattari (1972/1977) believe in the dismantling of contemporary theories through counter assumptions and celebration of difference and plurality in everything, including self-identity and day to day lived experiences (p. 76). For Best and Kellner, both Deleuze and Guattari highlight emergence of fresh "decentred subjects" (p.78), and look at the world through the lens of their key concept i.e. rhizomes, which is closely relevant to this research. They define the term Rizome as "decentred lines that constitute multiplicities" (p.99) and give language power to open up to manifold interpretations. Further, Best and Kellner elucidate that the postmodern notions, "the Schizos, Rhizome and Nomad are all variations on the postmodern theme of breaking with repressive" and established identities (p.103).

Deleuze's (1969/2004) criticism on the psychology of self is inspired by Foucault's postulation of authority. He disapproves modern notions of unity, rationality and repression, due to his faith in spiritual worth of multiplicity as Deleuze refers to "death and multiplicity" as real mystical strengths or actual spiritual happenings (p. 332). 


\section{Methodology}

This qualitative study is informed by Derrida's (1967/1976) deconstructionist ways of looking at the text. Deconstruction is also a reconstruction that questions certainty, identity and trust. Derrida through the interstitial space (aporia) challenges binary oppositions, which is very much related to the basic objective of this inquiry since it also seeks to resolve the crisis of Postmodernist schizoid self with its promises and perils by shunning the unjustified binary between males and females.

Echoing the same, Hussain (1994) recommends deconstruction as a methodological strategy, "which teases out the warring elements in the text" and facilitates in unearthing paradoxes as well as concealed and unconscious dreads that "underpin patriarchal discourse with regard to women" (p. 123), which again is the rationale of this study. The following methodological principles such as logocentricism (desire for a center), Difference (divided nature of the sign) and Aporia (selfcontradiction) would be used to decipher the meaning of schizoid self and also to resolve the paradox of the split self in this age of crisis specifically through the interstitial/intersectional link between gender and spirituality.

\section{Discussion and Analysis}

Khan (2008) opens The Geometry of God with Ibn Rushd's idea of soul, which, though is heavenly, divine, infinite, and undying, yet is unverifiable and also established as a fact beyond doubt. The human soul has no gender since, it is a distinct light that extends into positive or negative and constructive or destructive energies. As, Amal's Nana broadens her vision with the insight of a mystic and develops her "inner eye" (p.4) to look beyond physical world.

\section{Difference between Theoretical (Women) and Practical (Men) Outlook}

Nana elucidates two types of intellects as follows 'Aql nazari, which means the natural ability to imagine and 'aql amali' which is the quality to do (Amal) and to act. Anyone, who possesses this innate talent "to perform" can shape his/her own world. Nana understands men's ambition in life is as passionate as women's ambition is in the kitchen. The notion of "Difference", both as a theoretical lens and a methodological tool, seems at work in khan's (2008) common perception about the difference between imaginative faculty of women and pragmatic outlook of men, which are simultaneously contrary and complimentary. As, Nana shuns this stereotypical notion by calling both men and women equally ambitious, however, in different fields. Nana declares Amal as practical just like him- a restless soul, while Mehwish as imaginative and serene soul. Amal stands as a radical female against the traditional binary between men and women (faith and reason), that requires silence and total submission from females, as she asks Aba (father), why God has turned Mehwish blind? to this Aba advises, we "cannot question His will" (p.27). But, she contemplates just like her Nana, out of limits, "Did God make a mistake?" (p.27) by turning Mehwish blind and Why God has "given her eyes" if Mehwish is not going to use them? (p.27). This refers to the fact that the distinction between theoretical and practical outlook is not always gender bound as it is generally perceived, since human beings (men and women) are in a perpetual process of transforming and evolving.

\section{The Binary between Religion and Logical Reasoning}

Aba claims to be a devout Muslim, while Nana believes in scientific and logical reasoning. Amal started learning the first Urdu alphabet alif for Allah, but, Nana instantly corrected her "alif is for aql" (p.6). Contrary to this, Aba retaliated by asserting the primacy of Allah before everything even intelligence (aql). Here, we find another binary between alif-Allah and alif-aql, which once again is neuter gender as Aba even as a logical male thinks, if Amal learns alif-aqal, she will put herself before Allah. Nana as usual teases Aba by reminding him, aql starts with (ayin-urdu), which is "twentyfourth" alphabet in Urdu. Then, Nana asks Aba the meaning of "a real Pakistani"? (p.6) and, continues pestering him on speaking Urdu to "be a real Pakistani" and Punjabi to be "twice as Pakistani" or English to be "half as Pakistani" (p.6). At this point, we need to remember that the definitions of both Nana and Aba are not fossilized, but fluid and flexible due to their contradictory nature. Here, the interstitial space deconstructs the traditional binaries between self and other (male and female) and thus opens space for plurality and multiplicity of voices through tolerance and thereby resolves the crisis of human self which is schizoid and split due to lack of understanding self and other.

In the wake of human transition, Nana believes in the fluidity of religious and spiritual experiences and also identifies the "fixed moments" (p.7) of Muslim observatories, due to which 
stability is required in this world. For this, Nana illustrates his sense of direction led by his mystic sense for whom the world itself is his "Ka' ba"- the dwelling place of God.

\section{The Difference between a Scientist and a Sufi}

Junayd explains the distinction between the level of intimacy of a scientist and a Sufi with God, the former does it as a lapsed one, while, the latter does it for his/her intensity of love to God. Junayd declares too much "intimacy with God" is forbidden because going beyond time and space is a heathen act. But, Nana negates it declaring "union with the Beloved" is not an act of sinning (p.8). For this, Nana explains the role of a Sufi, as a real "evolutionist" (p.8) since he strives to reach God through self-annihilation. Junayd finds the self-destruction of a Sufi as a self-designing, which becomes an act of contention than of "submission to God" (p.8). But, for Nana, a Sufi submits due to his love and devotion as he/she can't imagine to compete with the Beloved. Nana goes on arguing that the real must be united with the imagined because the creator and the creation can't be separated from each other, this again calls for a peaceful co-existence in which each singular part contributes to the whole.

Noman's father takes religion strictly and stops greeting Sikhs at Gurdwara (holy place for Sikhs) due to lack of religious tolerance and pluralism in his outlook. Apparently, Noman follows his father, but, inwardly he has his own algebraic sense of observation. As, he deduces the departure of God from Pakistan due to extremist tendencies in religious and social conduct of people, since Islam upholds moderation and subverts radicalism and strictness. Thus, for Khan (2008), the departure of true Islamic ideology from Pakistan also made Aba to lose tolerance for others within and outside his faith.

\section{An Islamic Angel Vs. A Scientific Devil.}

Aba whispers like a pure angel and instructs Noman to go and silently record the speech of the devil "bhainchod" [sister-fucker] Zahoor (p.79). Here, we can perceive clear contradiction in the theory and practice of Islamic ideology. Aba claiming to be a true Muslim abuses Zahoor for his scientific knowledge, which is strictly prohibited in Islam, as Quran does not allow being abusive in one's sayings and doings. Then, how can a sincere Muslim so conveniently abuse others? Noman's Aba lacks spirituality in his religious conduct and Zahoor also makes fun of religious beliefs to the point of heresy and proves primacy of science, which is both authoritative and extremist. Since, Islam shuns extremes and promotes moderation, thus, both Aba and Nana- Zoo-Whore (Aba calls Nana) become at some point split and schizoid. In a similar manner, Khan and Akram (2019) highlight this selfcontradictory state of both Aba and Nana by bringing forth Junayd's "alternative to this conflict" that is a "composite view of reality with its rational and spiritual dimensions" which they lack due to their "unipolar outlook" (p.52). In order to deal with this split and schizoid state of both religious and secular males and females, there is a need to strike a balance between faith and reason to pacify the situation by embracing plurality and diversity, which khan (2008) seems to leave unresolved.

\section{The Rift between Eastern and Western Mindset}

Noman's Aba does not like mixing up males and females as for him, it is equal to "Pornography, obscenity, women in sports and advertising" (p.23) and these prohibited practices are getting popular against the spirit of Islam, as, Muslims are not supposed to take pleasure in profanity. Thus, Aba struggles to bring Islam in educational system to save Pakistani youth, who, under the influence of the West, science and films is becoming capricious in his religion and "a cultural freak!" in his life style (p.23). On this self-contradiction of Aba, Noman's sister Sehr reminds Aba of his liking for Punjabi films of Anjuman, Ama intervenes and snubs her, as questioning authority is not less than a sin and Aba is the sole authority of the home.

Contrary to Aba, Nana deconstructs this unjustified and man-made divide between East and West, in the name of religion. People call Nana "Western" due to his love for science (p.38) but, Nana shuns this binary by posing solid questions: do scientific findings only pertain to the West? Do we remember Omar Khayyam's contribution of giving us an accurate calendar? What about "Al Zahrawi" and also about "antiseptics"? (p.38) Do they also belong to the West? It is unfortunate to know that we have lost our scientific legacy. Even Aba of Amal doubts Nana's status as a believer due to his scientific bent of mind. Here, Khan (2008) presents conflicting views of two male characters from East to highlight the rift between Eastern and Western mindsets, which once again is neither gender nor country bound like always. 


\section{Opposites are as Necessary as Impossible}

The opposite views bring conflict in society, but, opposites are necessary in constructing a balanced society. For, instance, Apa Farzana explains Quranic concept as following, "Glory to Allah who created in pairs all things" (p.31). She furthers that everything comes in pairs, and "without opposites" (p.31), there is no sex and society possible. Amal also contemplates, what can be the opposite of herself? It shows that opposites are not always contradictory, but complimentary for human survival, as Nana criticizes divisions, since divisions are against the principle of co-existence. According to him, people can go extra miles for "divisions" in their minds and even can kill others (p.39).

\section{Difference between Physical and Intellectual Blindness}

Noman's father instructs him to rewrite the story of Zahoor (Nana) that makes Noman morally and spiritually blind as, in so doing, he ignores his own intellectual worth. Though, Noman is not physically blind like Mehwish, yet, mentally he feels blank under the domination of his own father. Here, gender is not the real issue, but, the power dynamics, as even, a male head with his utmost power can control and dominate another male as his subordinate, just like Noman's father. The same can go for the domination of Western ideologies over Eastern mindsets. As, there is a "white" man's myth of less hair that "the white man is more intelligent because he's less hairy" (p.64) and this can be deconstructed by witnessing many white furry apes, like Petrov in this novel.

\section{Pakistani Youth in a State of Spiritual Crisis}

Noman's Aba considers Pakistani youth as "cultural freak" (p.75) because, it easily loses its nerves for its ardent devotion to Pakistani culture just like an addict. For Aba, Pakistani youth has whimsical religious beliefs due to lack of direction and straight path. He continues enunciating Pakistani youth as "split" (p.75) and clearly states that a young Pakistani can be pulled easily even by "a small wind" (p.75), because, the minds of youth have been emptied to leave the country. He also asks about young Pakistanis, who do not leave and stay here, but with empty and weak brain, who has drained their brain? Aba believes that Pakistani youth is suffering from spiritual sickness and is in need of filling the gaps in their spiritual knowledge and this evil is spreading through educational books, which is attempting to divert the youth away from "Truth" (p.75). Thus, Aba just like a controlling freak forcefully tries to take the privilege as an elder to control the lost youth. This state of crisis can be taken both literally and ironically due to the postmodernist interstitial space, which mixes facts and fiction and offers multiple interpretations. As, Islam is not forceful in its ethics, but these are our cultural constructs that we try to impose on others under the banner of religion. Thus, we divide into various cultural, physical and social categories, which are definitely not spiritual because for God, the best of the best is the one, who is good for one and another regardless of gender, ethnicity, language and culture.

\section{Science for Women}

Amal as a female adult is supposed to have a male guard, if she wishes to join scientific field, since, it is infeasible for females in East to travel alone safely as compared to West, where women have more public security. Thus, Amal faces a lot of challenges as a female scientist and many questions arise, Is there anything to do with the gender of the scientist? Is it a religious or a social demarcation? No man wants Amal in the lab as a competitor, but, if she can add some beauty to the lab, then, the matter would be different. Amal envies Mehwish for her blindness to this male/female discrimination and thinks that Mehwish is lucky "for not knowing the spaces unavailable to her" (p.109). Amal realizes that here, a girl reading rocks is "a silly girl" (p.207), while, getting married is more apt for her, that is equal to "Mahshallah" [God's Majesty] (p.207). She waited so long to work with men "as an equal" (p.302) because she does not want to give men satisfaction of seeing her crying "like a girl" (p.302). Khan (2008) presents Amal as a radical female, who wants to have an open space for her to get some balance and fresh air and also to shun the traditional stereotyping. But, in this attempt, she gets distracted and frustrated as she could not stop herself from having a physical relationship with Omar even before their marriage (p.305) and it intensifies her conflict instead of neutralizing it. Here, this study proposes that both men and women must keep their limits intact by maintaining a tolerant and moderate behaviour without demeaning each other in order to impart harmony through pluralism and bring spiritual rebirth for resolving the human crisis, which though is difficult but not impossible.

\section{Male and Female Offspring as Gifts from God.}

It is a common practice to celebrate the birth of a male offspring as compared to a female. Who has made this binary of fortune and misfortune between males and females? It is definitely not any 
religion as religion has nothing to do with this unjust discrimination, as Quran clarifies: "He bestows the gift of female offspring on whomever He wills, and the gift of male offspring on whomever $\mathrm{He}$ wills" (as cited in Khan, 2008, p.112).

\section{Silences and Absences for Men and Women}

Human beings are in a state of collective catastrophe, regardless of their gender, consequently, everyone suffers from identity crisis and finds something missing in life. As, Noman is a male, though, he follows his own mathematical designs of life, yet, he finds something absent in himself because he feels divided, split and fragmented, between faith and reason, as, he calls himself "an island" but without "a synthesis" and also "a cultural freak" but with full of absences (p.122). Then, females are supposed to be silent, if, something strange happens to them because they have double responsibility of maintaining the honour of themselves and their family. Mehwish does not share about the violent happening with anyone and maintains her silence just as Amal did, when, she had her first horrible exposure to the male genitals and harassment. The mishap of sexual abuse turned Mehwish into a silent woman from a naughty girl, as suddenly she grows and evolves due to her exposure to the outside world (p.285).

\section{Plurality and Inclusivism in Islam}

The unjust distinctions make the human society schizoid and fragmented since unwarranted binaries are only man-made as Islam welcomes and celebrates all, and thus offers a plural and diverse society free from conflicts, splits and excessive bifurcations. Abdul discusses about the plural and allinclusive approach of Islam, for him, "Islam embraces all" (p.249) and women too. He refers to the attitude of Christians and Hindus towards females and argues that it was the practice of Christian kings to divorce their "wives" and of Hindus to burn widows, but Islam showed care and respect for women. According to Abdul, in Islam women have been given all the rights, if, they keep up their purity. Then, he offers Amal his protection, which, as a female she needs. Here, the interstitial space undercuts and destabilizes the single meaning of the debate and suggests multiple angles, at this point Abdul's debate seems fractured as Amal understands and admits that she is "a woman first" (p.249) and nothing can change it. She realizes that men try to control women by pretending to be their protectors and also by calling women "mujboor Helpless" (p.250). She reflects, for people, men are equal to "macrocosm" (vast-universal), while, women are equal to "microcosm" (small- limited) (p.250), thus, she feels lost between traditional and radical conflicts and her struggle goes on as she fails to keep a balance between faith and reason. On the contrary, Noman gets peace after spiritually being united with Mehwish, unlike Nana, who is shot dead and more like Junayd, who too is shot dead but gets peace due to his tolerance, compassion and sacrifice for others. Khan (2008) leaves the conflict unresolved by presenting multiple angles to the debate through her split and fragmented characters and opens a room for manifold interpretations.

\section{Conclusion}

This study concludes that individuality is a transformational process which is unfixed and is in a constant circular process of growing, changing and developing in relation to self, other, gender and spirituality. Subsequently, the Postmodernist schizoid self (male and female) unfolds itself for renewal and unfurls like a blooming flower. Thus, this study directs us to achieve a mutual level of understanding, sharing and caring by acknowledging and respecting the perspective of each entity in order to complete a plural, diverse and an all-inclusive circle of life. The present inquiry proposes a fresh view of equality, justice and uniformity of different viewpoints in every field of life through interstitial and intersectional space of self, gender and spirituality that opens up new avenues of hope to resolve the dilemma of schizoid self. This study is recommended, as it is not only beneficial for transforming human beings socially and spiritually, but it is also academically ground-breaking in literary studies. Moreover, it offers open space for future research by indorsing fusion of Eastern and Western perceptions regarding the circular relationship between self, gender and spirituality, hence it has the potential to promote tolerance, compassion and peace both locally and globally due to its plural, diverse and all inclusive approach, which is the foundation of human cultures.

\section{References}

Aftab, A. (2011). Gender politics falsifying reality: Feminism another perspective. Islamabad: Emel Publications.

Aftab, A., \& Akram, S. (2019). "Dialectics of tension between politics and reason in Pakistani cultural landscape: A Critical reading of Uzma Aslam Khan's The geometry of God". Pakistan 
Journal of Languages and Translation Studies, UOG, 1(7), 38-56. https://www.uog.edu.pk/ en/research/PJLTS/\#

Ahmed, D. S. (1994). Introduction. In Masculinity, rationality and religion: A feminist perspective (pp.1-10).Lahore: ASR Publications.

Ahmed, D. S. (2002). Gendering the spirit: Women, religion \& the post-colonial response. London: Zed Books Ltd.

Akram, S. (2012). Concept of self and subjective consciousness in Walt Whitman and Bulleh Shah: A comparative hermeneutical analysis (Unpublished M.Phil. dissertation). Government College University, Faisalabad, Pakistan.

Akram, S. (2019). The spiral of self: An introspective encounter of Eastern and Western Mystic philosophies. Islamabad: Emel Publications Islamabad.

Al-Arabi, I. (1980). Fusus al-Hikam [The bezels of wisdom] (R. W. J. Austin, Trans.). New York: Paulist Press. (Original work published 1229a).

Al-Arabi, I. (1984). Fusus al-Hikam [The bezels of wisdom], The feminine dimensions in Ibn Arabi's thought. Journal of the Muhyiddin Ibn Arabi Society, 2, 8-9. (Original work published $1229 \mathrm{~b})$.

Aristotle. (1921). The works of Aristotle: Politica / by Benjamin Jowett. Oeconomica / by E.S. Forster. Athenensium respublica / by Frederic G. Kenyon. Vol. 10 (B. Jowett, Trans.). W. D. Ross (Ed.).Oxford: Oxford University Press/Clarendon Press. (Original work published 1254b).

Beauvoir, S. D. (2011). Le Deuxième Sexe [The second sex] (C. Borde, \& S. M. Chevallier, Trans.). New York: Vintage. (Original work published 1949).

Bell, J. S., \& Littleton, J. G. (2007). Living the Serenity prayer: True stories of acceptance, courage, and wisdom. Massachusetts: Adams Media Corporation.

Best, S., \& Kellner, D. (1991). Deleuze and Guattari: Schizos, nomads, rhizomes. In Critical interrogations (pp. 76-110). New York: Guilford Press.

Deleuze, G. (2004). Logique du sens [Logic of sense] (M. Lester, \& C. Stivale, Trans.). C. V. Boundas (Ed.). London \& New York: Continuum. (Original work published 1969).

Deleuze, G., \& Guattari, F. (1977). Capitalisme et schizophrénie. L'anti-CEdipe [Anti-Oedipus: Capitalism and Schizophrenia] (R. Hurley, M. Seem, \& H. R. Lane, Trans.). Minneapolis: University of Minnesota Press. (Original work published 1972).

Derrida, J. (1976). De la grammatologie [Of grammatology] (G. C. Spivak, Trans.). Baltimore \& London: Johns Hopkins University Press. (Original work published 1967).

Felluga, D. F. (2015). Critical theory: The key concepts (Routledge key guides). New York: Routledge.

Frick, G. D., Qasmi, A. U., \& Rostetter, K. (Eds.). (2011). Revisioning Iqbal: As a poet and Muslim political thinker. New York: Oxford University Press.

Gadamer, H- G. (2004). Wahrheit und Methode [Truth and method] (J. Weinsheimer, \& D. G. Marshall, Trans.) (2nd ed.). New York: The Continuum International Publishing Group, Inc. (Original work published 1960, 1989).

Gutting, G. (2005). Foucault: A very short introduction. New York: Oxford University Press.

Hussain, N. (1994). Women as objects and women as subjects within fundamentalist discourse. In N. S. Khan, R. Saigol, \& A. S. Zia (Eds.), Locating the self: Perspectives on women and multiple identities (pp. 108-133). Lahore: ASR Publications.

Inayatullah, S., \& Boxwell, G. (Eds.). (2003). Introduction. In Islam, Postmodernism and other futures: A Ziauddin Sardar reader (pp.1-23). London: Pluto Press

Iqbal, M. (2003). Iqbal's letters to Nicholson. In I. Waheed (Ed.), Hundred years of Iqbal studies (p. 193). Islamabad: Pakistan Academy of Letters.

Khan, N. S., Saigol, R., \& Zia, A. S. (Eds.). (1994). Introduction. In Locating the self: Perspectives on women and multiple identities (pp. 1-19). Lahore: ASR Publications.

Khan, U. A. (2008). The geometry of God. New Delhi: Rupa and Co.

Lyotard, J. F. (1984). La condition postmoderne: rapport sur le savoir [The postmodern condition: A report on knowledge] (G. Bennington, \& B. Massumi, Trans.). Manchester: Manchester University Press. (Original work published 1979). 
Lyotard, J. F. (1988). Le Différend [The differend: Phrases in dispute] (G. V. D. Abbeele, Trans.). Minneapolis: University of Minnesota Press. (Original work published 1983).

Nietzsche, F. (2008). Part1: xviii. Old and young women. In Thus spake zarathustra [A book for All and none] (T. Common, Trans.)(2nd ed.).Retrieved from https://www.gutenberg.org/files/ 1998/1998-h/1998-h.htm. (Original work published 1885).

Pickthall, M. M. (1930). The meaning of the glorious Qur'an. Retrieved March, 2, 2011 at 12:00 a: m, from http://www.comp.leeds.ac.uk/nora/html/3-14.html

Ricoeur, P. (1994). Soi-même comme un autre [Oneself as another] (K. Blamey, Trans.).Chicago: University of Chicago Press. (Original work published 1986).

Roald, A. S. (2001). Preface. In Women in Islam: The Western experience (pp. iix-xv).London: Routledge.

Russell, B. (1945). History of western philosophy. New York: Simon \& Schuster.

Sardar, Z. (1988). Dawa and development in Muslim world: The future perspective [Conference session]. Muslim world league, The manifesto, International Islamic conference, Makkah al Mukarrmah.

Sharma, R. (2016). Who will cry when you die? : Life lessons from the Monk who sold his Ferrari (2nd ed.). Mumbai: Jaico Publishing House.

Soul, M. A. (2015). Reflection of a man. Burbank: Black Castle Media Group.

Tolle, E. (2016). A new earth: Create A better life (2nd ed.). Penguin Random House UK.

Watson, J. B. (1928). The ways of behaviorism. New York: Harper \& Brothers. 